TAO, Vol. 17, No. 1, 169-178, March 2006

\title{
Crustal Stress and Strain Energy Density Rates in South Korea Deduced from GPS Observations
}

\author{
Shuanggen $\mathrm{Jin}^{1,2, *}$ and Pil-Ho Park ${ }^{1}$ \\ (Manuscript received 20 July 2005, in final form 17 November 2005)
}

\begin{abstract}
An accurate measurement and understanding of horizontal stress rates within the earth's crust is important for providing fundamental insights into the mechanisms driving plate motion and intraplate tectonic activity. In this paper, the stress field within the crust of the South Korean peninsula is obtained from observed displacement rates based on 4-year continuous GPS observations (2000 - 2004). Results show that the South Korean peninsula is under both compression and extensional stress regimes with maximum shear stress rate being in the mid part of the study area coinciding with the geologically defined Honam Shear Zone (HSZ) and relatively highly seismically active zone. In addition, the variation rate of strain energy density, an important index reflecting the intensity of crustal activity, is further derived, and its distribution indicates high earthquake potential in the mid-part as well as the north and northeast edges of the crust of the South Korean peninsula.
\end{abstract}

(Key words: GPS, Stress rate, Strain energy density rates, South Korea)

\section{INTRODUCTION}

What determines intraplate tectonic activities and plate motions is still unknown. An accurate measurement and understanding of stress (distribution, pattern and intensity) probably provide some basic insight to this problem. The Korean peninsula is located in the northeastern Asian margin, between the Chinese continent and the Japanese Island Arc, which is perhaps subject to the subduction of the Philippine Sea and Pacific plates and the expulsion of the

\footnotetext{
${ }^{1}$ Space Geodesy Research Group, Korea Astronomy and Space Science Institute, Daejeon, South Korea

2 Shanghai Astronomical Observatory, Chinese Academy of Sciences, Shanghai, China

* Corresponding author address: Dr. Shuanggen Jin, Space Geodesy Research Group, Korea Astronomy and Space Science Institute, Daejeon, South Korea; E-mail: sgjin@kasi.re.kr
} 
Eurasian plate with the Indian plate collision (Molnar and Tapponnier 1975; Zonenshain and Savostin 1981; Kato et al. 1998; Kogan et al. 2000, Jin and Zhu 2003). The tectonic provinces of the South Korean peninsula include two Precambrian massifs: the Kyeonggi (KM) and Yeongnam (YM) massifs; three Paleozoic basins: the Pyeongnam (PB), Taebaeksan (TB) and Okcheon (OB) sedimentary basins; and the Imjingang Belt as well as the Honam Shear Zone (HSZ) (Fig. 1) (Hurley et al. 1973; Ernst et al. 1988; Choi et al. 1999; Kim and Lee 2000). These provinces have been regarded as a tectonically single terrane of South Korea (Chough et al. 2000). Although some scientists, such as Choi P.Y. et al. (1996), investigated palaeo-stress in South Korea utilizing geological data, the present-day kinematics of tectonic deformation in the Korean peninsula are still largely unknown due to a lack of real observation data. However, the existing permanent Korean GPS Network (KGN) provides an important data source for the investigation of the kinematics of tectonic activity on the South Korean peninsula. As tectonic activity is generated by stress, and the distribution and intensity of such stress can result in earthquakes, an accurate measurement of stress makes a significant contribution to revealing kinematical features and prediction of earthquake potential. In addition, the variation rate of strain energy density is an important index reflecting the intensity of crustal activity. For earthquake prediction, the key issues are the rapid estimation of stress from surface displacement

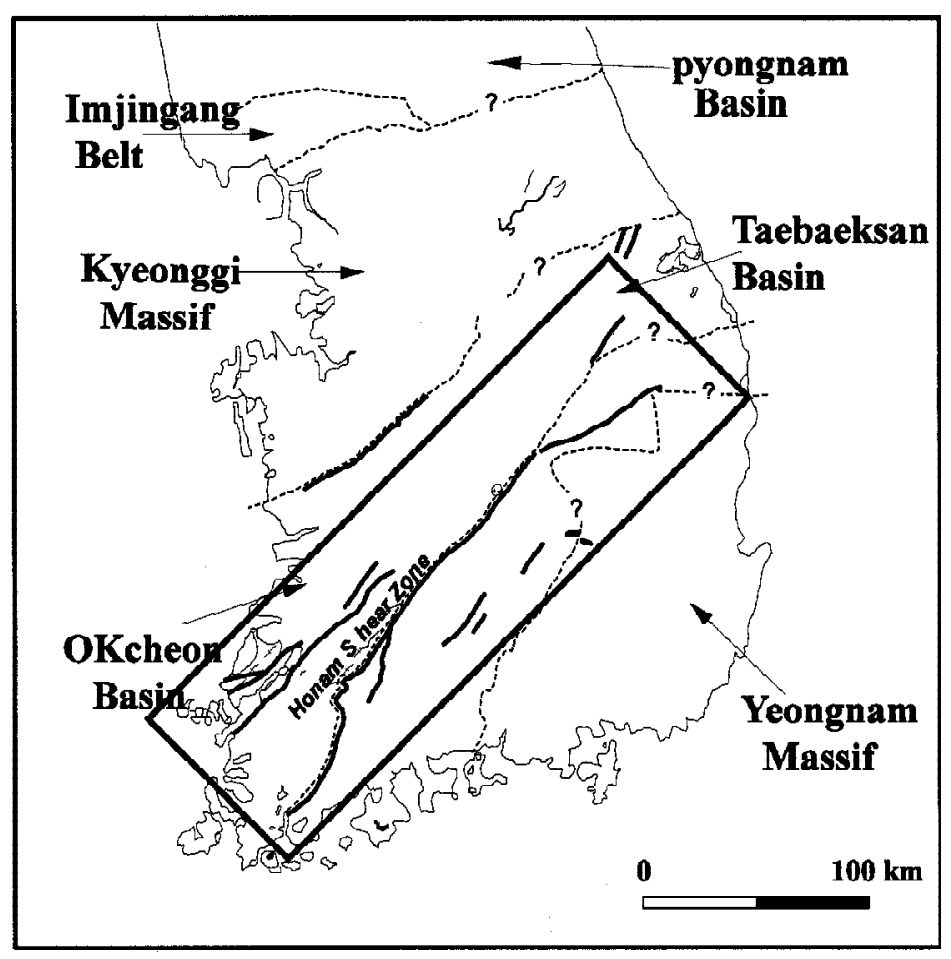

Fig. 1. Simplified tectonic map of South Korea, showing the Honam Shear zone, belts and basins. 
observations and the determination of the state of strain energy density within the crustal lithosphere and how it changes with time.

In this paper, we aim to estimate the stress field within the South Korean peninsula from 4-year continuous GPS observation data (2000 - 2004) of the permanent Korean GPS network (KGN); and analyze its distribution and pattern. The variation rate of strain energy density in the South Korean peninsula is further derived and discussed.

\section{GPS DISPLACEMENT RATE FIELD}

The permanent Korean GPS Network (KGN) (Fig. 2) was established in 2000 and provided continuous GPS observations allowing for investigation of crustal kinematics in the South Korean peninsula. We analyzed all available good data for the period March 2000 to February 2004 in the ITRF2000 reference frame (Altamimi et al. 2002) using GAMIT software (King and Bock 1999) with IGS precise orbits and IGS Earth Rotation Parameters. The site displacement velocities were estimated by least square linear fitting to time variation of the daily coordinates for each station. The 1-sigma of estimated velocity in each station is $0.7-0.9 \mathrm{~mm} \mathrm{yr}^{-1}$ for the NS component and $0.3-1.9 \mathrm{~mm} \mathrm{yr}^{-1}$ for the EW-component, and the motion rates of all sites in South Korea are $32-35 \mathrm{~mm} \mathrm{yr}^{-1}$ in the ITRF200. As the velocities with respect to the stable Eurasian plate (NNR-NUVEL-1B, Jin and Zhu 2004) are about 7 - $9 \mathrm{~mm} \mathrm{yr}^{-1}$, crustal-motion features are not obvious. Deformation rates relative to a stable site, IGS SUWN, are obtained and shown in Fig. 2. The motions of all GPS sites rotate anti-clockwise with respect to the IGS SUWN site. In addition, it has seen that the South Korean peninsula exhibits an E-W compression trend, and a S-N slightly extensional trend.

\section{STRESS RATE FIELD}

In order to understand detailed kinematic features, it is essential to know the stress state. As the first step in the stress inversion, the strain field in each triangle subnetwork is derived from the above estimated GPS displacement rate field. Due to poor vertical estimates of GPS displacement rates, we only use the horizontal velocity field of the KGN in Fig. 2 to estimate the horizontal strain parameters of each triangle subnetwork by connecting the adjacent three GPS sites. Then the stress rate is further obtained through the laws of elasticity theory as follows (Straub 1996; Xu et al. 2002):

$$
\dot{\sigma}_{i j}=2 \mu \dot{\varepsilon}_{i j}+\delta_{i j} \lambda \dot{\Delta}
$$

where $\dot{\sigma}_{i j}$ and $\dot{\varepsilon}_{i j}$ are the stress rate and strain rate, respectively, $\mu$ is the modulus of rigidity, $\lambda$ is the Lame parameter, $\delta_{i j}$ is Kroneckerdelta, and $\dot{\Delta}$ is the 2-D surface dilation rate $\left(\sum \varepsilon_{i i}\right)$. The elastic behavior of crust lithosphere can be characterized by specifying either $\mu$ and $i=\lambda$ or $E$ (Young's modulus) and $v$ (Poisson's ratio). The Lame parameter $\lambda$ is expressed in terms of the rigidity $\mu$ and Poisson's ratio $v$ as $\lambda=2 \mu v(1-2 v)^{-1}$. Generally, Poisson's ratio $v$ is as- 


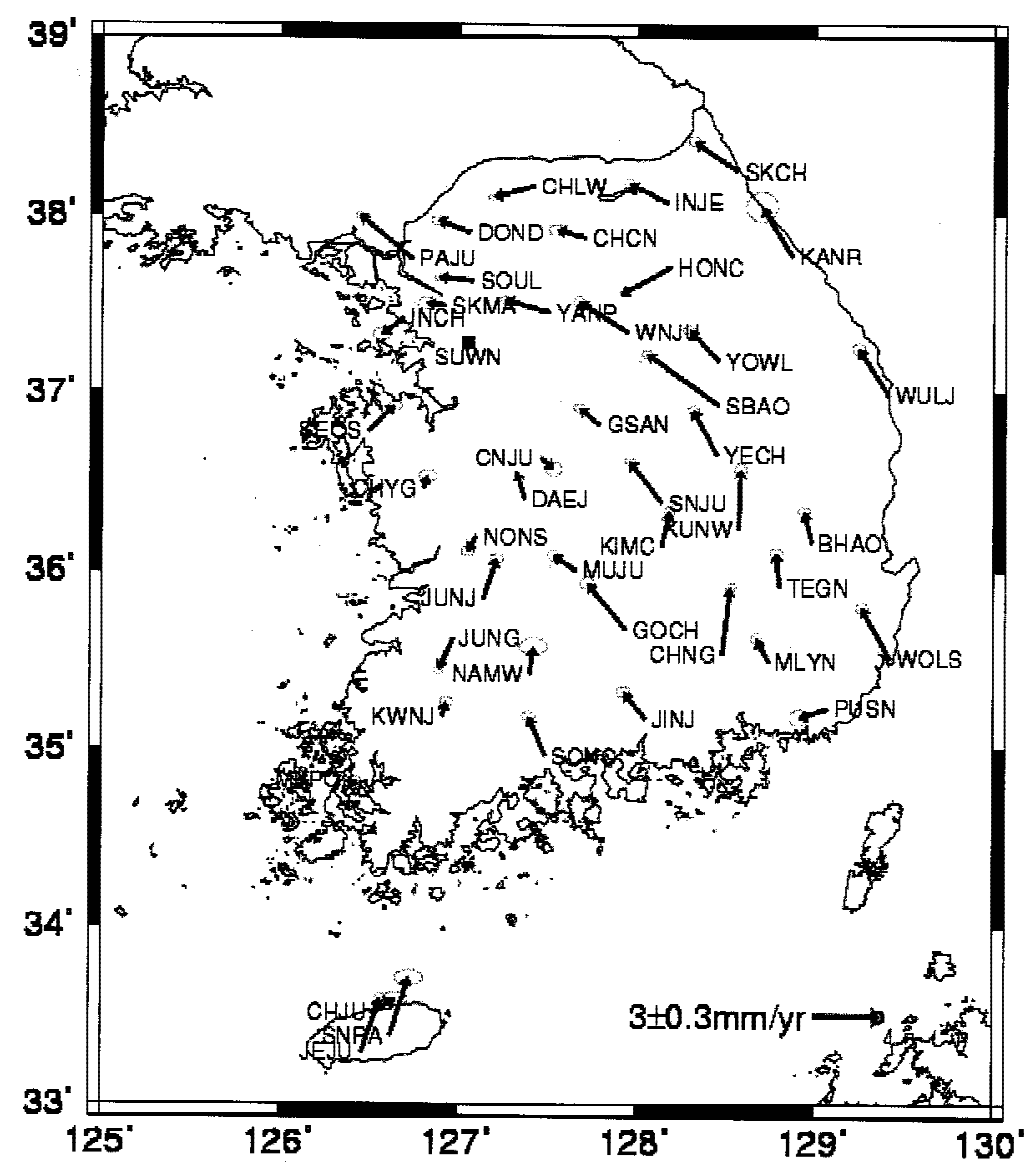

Fig. 2. Deformation rates in South Korea relative to the IGS SUWN site (square shape). Error ellipses are $95 \%$ confidence limits.

sumed to be 0.25 for crustal rock and the modulus of rigidity adopts the standard value of $3 \times 10^{10} \mathrm{~Pa}$ (Hanks and Kanamori 1979). Thus, the stress field can be obtained. The principle axes of stress rates are shown in Fig. 3. The principal axes of extension and compression stress rates are mainly in the NNW-SSE and ENE-WSW directions, respectively. The pattern and distribution of stress rate show that South Korea is obviously dominated by extension stress rates in NNW-SSE direction and compression stress rates in ENE-WSW direction, coinciding with the focal mechanism of earthquakes in and around South Korea (see Fig. 6: solid and open quadrants are extension and compression, respectively). The magnitude of stress rates are wholly small being two orders of magnitude smaller than the stress rates of about $100 \mathrm{kpa} \mathrm{yr}^{-1}$ in areas of high crustal activity in the Japanese islands (Iinuma et al. 2005); this indicates lower and less seismic activity in South Korea (Kim and Lee 2000). 


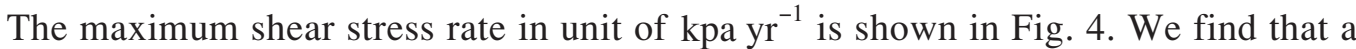
remarkable shear trend with high stress rates focuses on the mid part of the South Korean peninsula with a direction NE-SW coinciding with the Honam Shear Zone (HSZ); this is a highly seismically active region. A dilatation stress rate contour map of the region is shown in Fig. 5, the negative value (dash line) represents compression and the positive value (solid line) stands for extension. It is clearly seen that the South Korean peninsula has both compression and extensional stress rates dominating different areas. A compression stress regime exists in the western and eastern parts of the peninsula and an extensional stress regime is in the northern and southern parts of the study area. The compression stress regime may be due to collision with the SW Japanese Island Arc and the eastward expulsion of the China continental block by the collision with India to the north. Such stress leads to corresponding strain. As the stress rates are estimated from GPS observed strain rates through the laws of elasticity theory, the strain pattern and distribution are almost the same as stress ones (Figs. 3, 4 and 5).

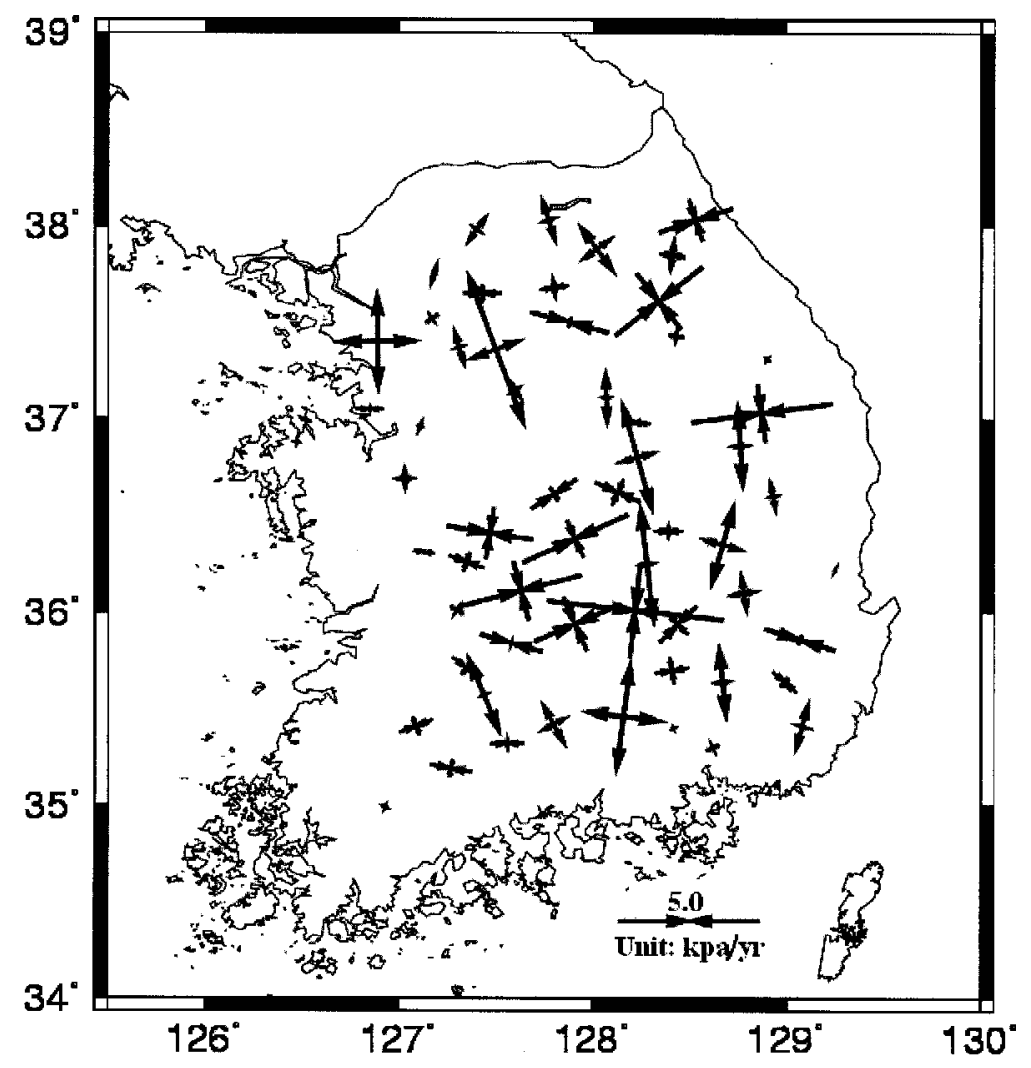

Fig. 3. Principal horizontal axes of the stress rate tensor in South Korea obtained from the GPS velocity field. The convergent arrows are contraction and the divergent arrows are extension. 


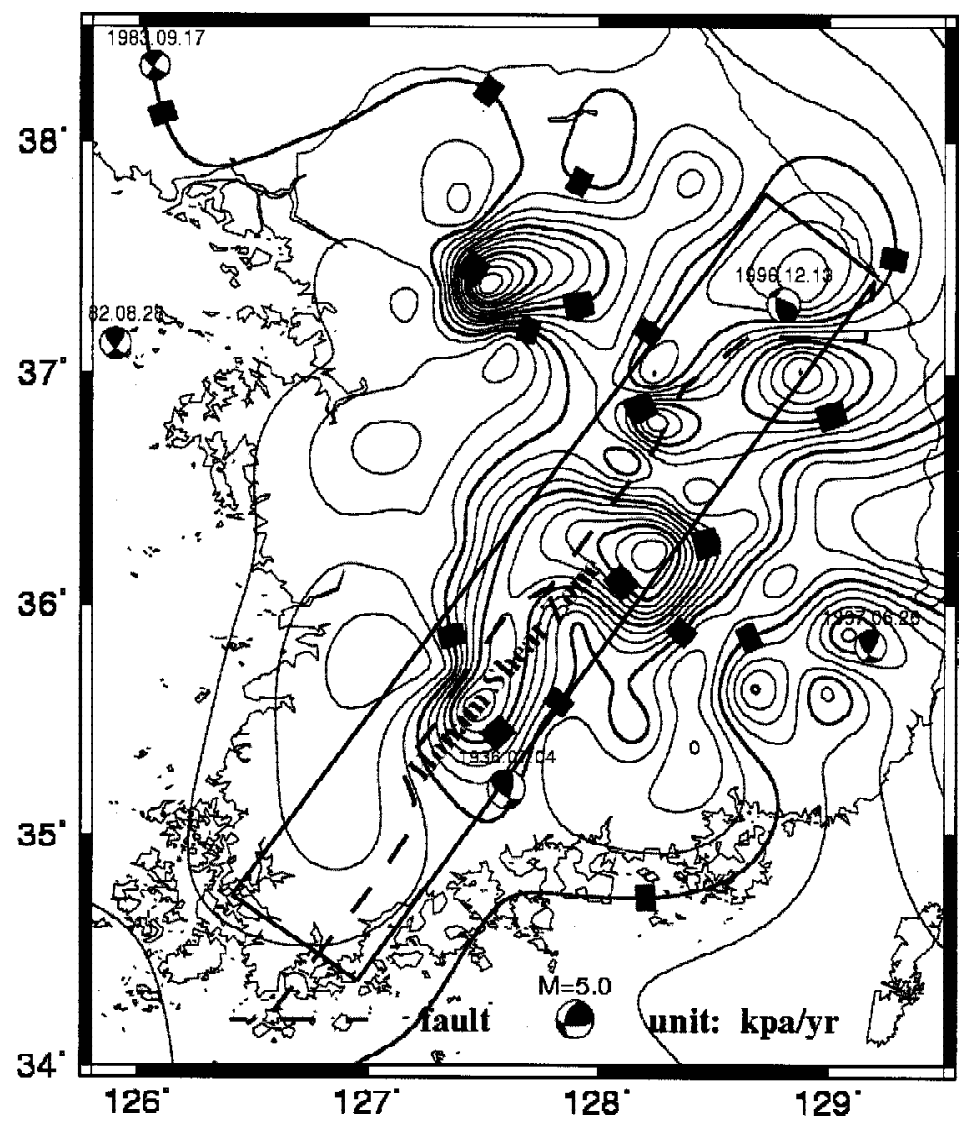

Fig. 4. Contour map of maximum shear stress rates in the South Korean peninsula, fault line and seismicities that occurred in the period from 1936 to the end of 2004 with $M_{w} \geq 4.0$ in and around South Korea.

\section{STRAIN ENERGY DENSITY VARIATIONS}

Accumulated strain energy is generally released through earthquakes until adjacent fault blocks or plates reach a new state of equilibrium. The release of tectonic strain energy stored within crustal rock is the cause of major earthquakes. Strain energy per unit (i.e., the strain energy density) is an important index reflecting the intensity of crustal activity; and its variation rate indicates the trend of accumulated energy within the crust. The larger the variation rate of strain energy density, the higher the energy accumulated in the crust which will more probably result in earthquakes. Therefore, for earthquake prediction, it is important to rapidly estimate the strain energy density from surface displacement observations, and then determine the state of strain energy density within the crust, and how it changes with time.

For an elastic body, the strain energy equals the work done by external forces, and its 


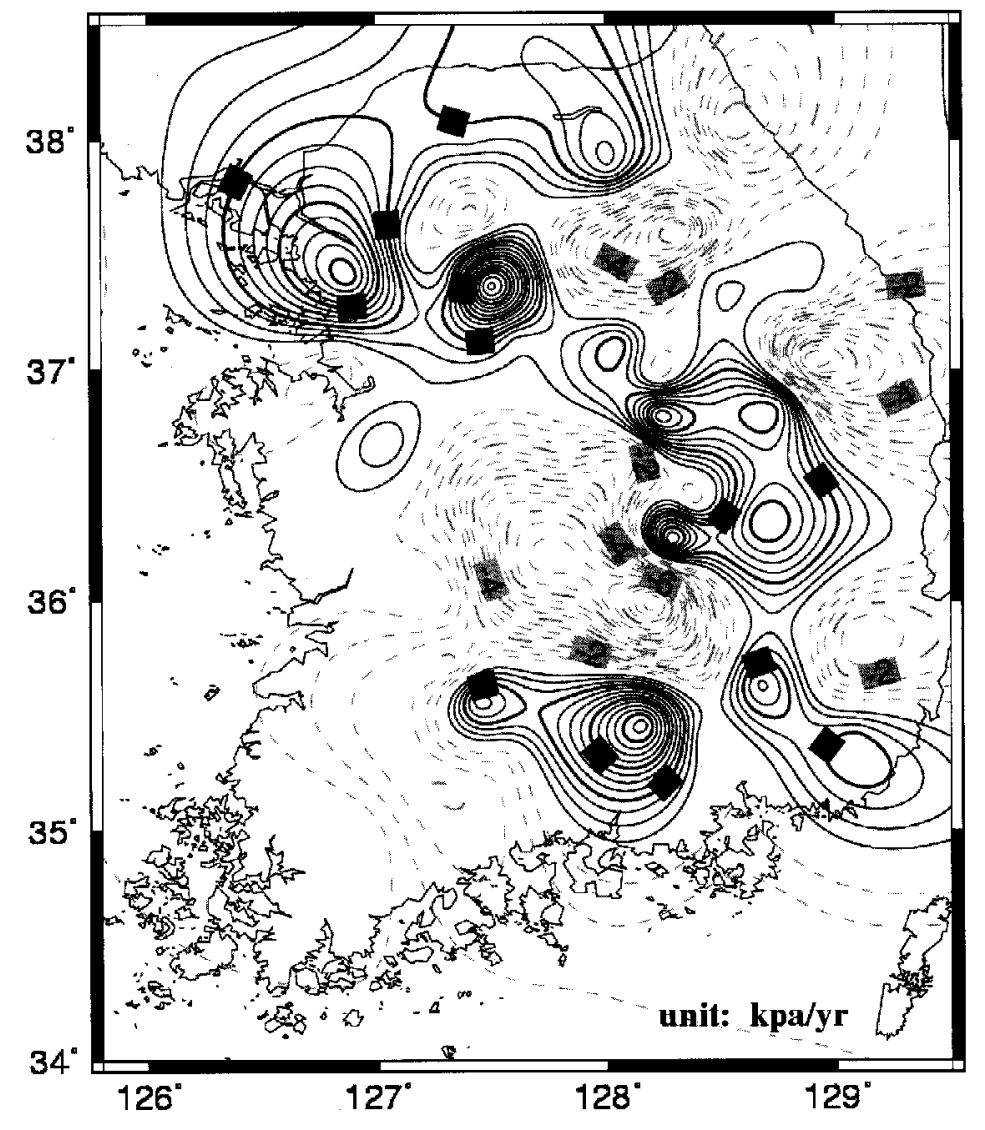

Fig. 5. Contour map of dilation stress rates in the South Korean peninsula.

density is the strain energy per unit volume. The general tensor form for strain energy density can be expressed in terms of strain and stress using Hooker's Law:

$$
U=\frac{1}{2} \sigma_{i j} \varepsilon_{i j}
$$

where $U$ is the strain energy density (Unit: $\mathrm{J} \mathrm{m}^{-3}$ ), and $\sigma_{i j}$ and $\varepsilon_{i j}$ are the stress and strain, respectively. The variation rate of strain energy density can be further derived from Eq. (2), namely:

$$
\dot{U}=\frac{1}{2}\left(\dot{\sigma}_{i j} \varepsilon_{i j}+\sigma_{i j} \dot{\varepsilon}_{i j}\right),
$$


where $\dot{U}$ is the variation rate of the strain energy density (Unit: $\mathrm{J} \mathrm{m}^{-3} \mathrm{yr}^{-1}$ ), and $\dot{\sigma}_{i j}$ and $\dot{\varepsilon}_{i j}$ are the stress rate and strain rate, respectively. Thus, the strain energy density variation rate in South Korea can be obtained using derived strain and stress and their rates, and is shown in Fig. 6. The distribution of strain energy density variation rates shows that the most crustal active areas are in the mid part, and northern and northeastern edges of the South Korean peninsula. These results almost locate at the main geological faults and highly seismically active zones in South Korea. As the GPS measurements are all almost made after the historically large earthquakes in Korea, the strain energy density rates derived from the GPS displacement rate are partly a consequence of postseismic relaxation, and further release by earthquakes is possible. Therefore, these regions with an anomalous large strain energy density rate probably indicate high earthquake risk in the future.

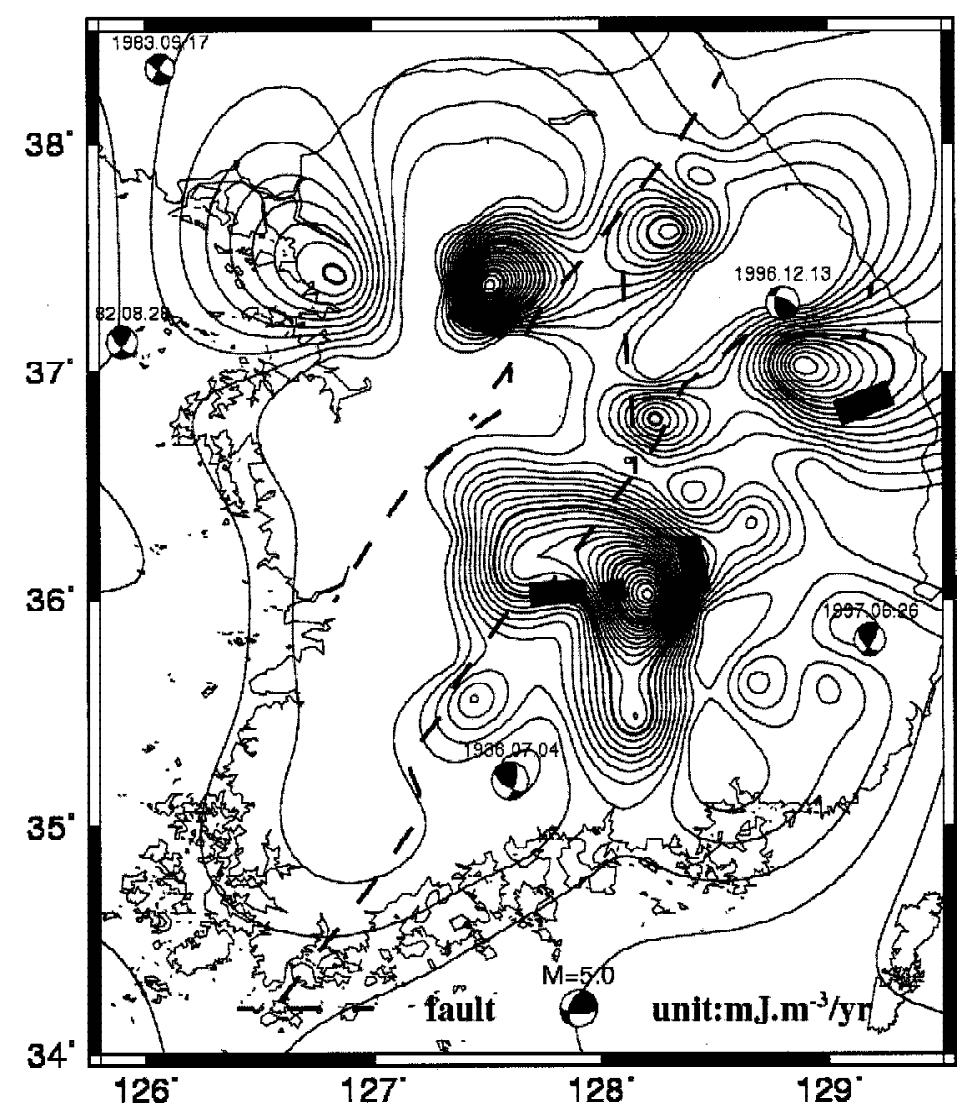

Fig. 6. Variation rate of crustal strain energy density, fault lines and seismicities that occurred in the period from 1936 to the end of 2004 with $M_{w} \geq 4.0$ in and around South Korea. 


\section{DISCUSSIONS AND CONCLUSIONS}

The stress and strain energy density rates of the South Korean peninsula were analyzed with 4-year continuous GPS observation data with the following conclusions: (1) The principal axes of stress rates indicate that the South Korean peninsula is affected by converging continental plates (China and Japan blocks); (2) Maximum shear stress rate is in the mid part of the area and almost consistent with geologically defined shear zones and high seismic activity zones; (3) Dilatational stress rates indicate that South Korea is under both compression and extensional stress regimes; (4) The distribution of strain energy density variation rates shows that the most crustal active areas are in the mid part, and northern and northeastern edges of the South Korean peninsula, indicating high earthquake risk in the future.

Because the stress and strain energy density rates are obtained from strain rates derived from a triangular GPS subnetwork, we further estimate stress and strain energy density rates from a quadrangular GPS subnetwork. Compared with the triangular subnetwork, it shows almost consistency in the distribution, patterns and strength of stress rates, but has a little difference, which may be caused by abnormal GPS motions. In addition, the results were obtained under the assumption of linear elasticity. Actually the lithosphere is not truly homogeneous, and this directly affects estimations of stress and strain energy density rates. Therefore, the results and speculations need to be further investigated with closer analysis using more available data with dense and long-term observations and consideration given to the heterogeneous crust of the South Korean peninsula.

Acknowledgements All figures were made with public domain software GMT (Wessel and Smith 1998). We are grateful to National Geographic Information Institute (NGII), and Ministry of Government Administration and Home Affairs (MOGAHA) and other members who made the observation data available. This work was supported by the Korean Ministry of Science and Technology under grants M2-0306-01-0004, M6-0404-00-0018 and M6-040400-0010.

\section{REFERENCES}

Altamimi, Z., P. Sillard, and C. Boucher, 2002: ITRF2000: A New Release of the International Terrestrial Reference Frame for Earth Science Applications. J. Geophys. Res., 107, 2214, doi: 10.1029/2001JB000561.

Choi, K. S., G. V. R. Kumar, and K. Y. Kim, 1999: Qualitative interpretation of Bouguer anomaly in the south part of the Korean peninsula. Geosci. J., 3, 49-54.

Choi, P. Y., J. Angelier, and J. H. Hwang, 1996: From shear structures to friction law: Similarity of natural stress tensor in brittle tectonics. Comptes Rendus Del Academie Des Sciences Serie II Fascicule A-Sciences Dela Terre Et Des Planetes, 322, 149-154.

Chough, S. K., S. T. Kwon, J. H. Ree, and D. H. Choi, 2000: Tectonic and sedimentary evolution of the Korean peninsula: a review and new view. Earth Sci. Rev., 52, 175235 . 
Ernst, W. G., R. Cao, and J. Jiang, 1988: Reconnaissance study of Precambrian metamorphic rocks, northwestern Sino-Korean shield, Peoples Republic of China. Geol. Soc. Am., 100, 692-701.

Hanks, T. C., and H. Kanamori, 1979: A moment-magnitude scale.J. Geophys. Res., 84, 2348-2350.

Hurley, P. M., H. W. Pinson, and J. H. Lee, 1973: Middle Precambrian and older apparent age values in the basement gneisses of South Korea and relations with Southern Japan. Geol. Soc. Am., 84, 2299-2304.

Iinuma, T., T. Kato, and M. Hori, 2005: Inversion of GPS velocity and seismicity data to yield changes in stress in the Japanese Islands. Geophys. J. Int., 160, 417-434.

Jin, S. G., and W. Y. Zhu, 2003: Active Motion of Tectonic Blocks in Eastern Asia: Evidence from GPS Measurements. ACTA Geol. Sinica-English Edi., 77, 59-63.

Jin, S. G., and W. Y. Zhu, 2004: A revision of the parameters of the NNR-NUVEL1A plate velocity model. J. Geodynamics, 38, 85-92.

Kato, T., Y. Kaotake, and S. Nakao, 1998: Initial results from WING, the continuous GPS network in the western Pacific area. Geophys. Res. Lett., 125, 369-372.

Kim, S. G., and K. S. Lee, 2000: Seismic risk map of Korea obtained by using South and North Korea Earthquake catalogues. J. Earthquake Eng. Soc. Korea, 4, 13-34.

Kogan, M. G., G. M. Steblov, R. W. King, T. A. Herring, D. I. Frolov, S. G. Erorov, V. Y. Levin, A. Lerner-Lam, and A. Jones, 2002: Geodetic constrains on the rigidity and relative motion of Eurasian and North American. Geophys. Res. Lett., 27, 2041-2044.

King R. W., and Y. Bock, 1999: Documentation for the GAMIT GPS Analysis Software, Mass. Inst. of Technol., Cambridge Mass.

Molnar, P., and P. Tapponnier, 1975: Cenozoic tectonic of Asia: effects of a continental collision. Sciences, 189, 419-426.

Straub, C., 1996: Recent crustal defoirmation and strain accumulation in the Marmara sea region, inferred from GPS measurements. Ist. of Geod. and Photogram. FTHZ Mitt. 58 $\mathrm{pp}$.

Wessel, P., and W. H. F. Smith, 1998: New, improved version of Generic Mapping Tools released: Eos, Trans. Am. Geophys. Union, 79, 579.

Xu, C. J., L. Dong, C. Shi, Y. X. Li, and X. K. Hu, 2002: A field of annual accumulation of strain energy density and it's tectonic activity in North China by GPS measurements. Chinese J. Geophy., 45, 517-526.

Zonenshain, L. P., and L. A. Savostin, 1981: Geodynamics of the Baikal rift zone and plate tectonics of Asia. Tectonophy., 76, 1-4. 